\title{
Severe acute pancreatitis caused by endoscopic ultrasonography-guided fine-needle biopsy of a pancreatic solid pseudopapillary neoplasm
}

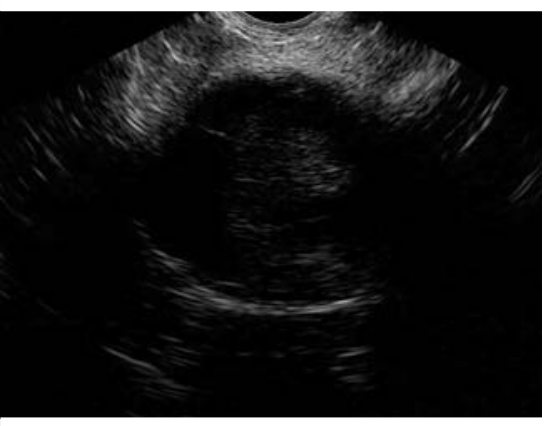

- Fig. 1 Endoscopic ultrasonography image showing a hypoechoic lesion in the tail of the pancreas.

A 33-year-old man was admitted to our hospital for investigation of a mass in the pancreatic tail found on computed tomography (CT) scan 3 months previously. Endoscopic ultrasonography (EUS) revealed a $3.0 \times 3.1-\mathrm{cm}$ hypoechoic lesion in the tail of the pancreas, with no wall nodules, separation, or communication with the pancreatic duct ( $\mathbf{F i g} .1$ ). EUSguided fine-needle biopsy (EUS-FNB) was performed with a 22G ultrasound biopsy needle with a side hole (ECHO-HD-22-C; Cook Echotip ProCore). We obtained sufficient tissue with no cystic fluid by puncturing the lesion three times, each time under 5-mL negative pressure with 15 to 20 insertions ( $\triangleright$ Video 1 ). The mass was eventually diagnosed as a solid pseudopapillary tumor on pathology with immunohistochemical staining ( $\mathbf{F i g . 2}$ ).

Unfortunately, the patient developed severe acute pancreatitis after undergoing the EUS-FNB. This was confirmed by an elevation in the patient's blood leukocyte and amylase levels, and on CT scanning ( Fig.3). His symptoms were accompanied by type I respiratory failure and high grade fever for 7 days, but the patient eventually recovered after continuous renal replacement therapy, along with other treatments.

Compared with EUS-guided fine-needle aspiration (EUS-FNA), EUS-FNB is more appropriate for the diagnosis of pancre-

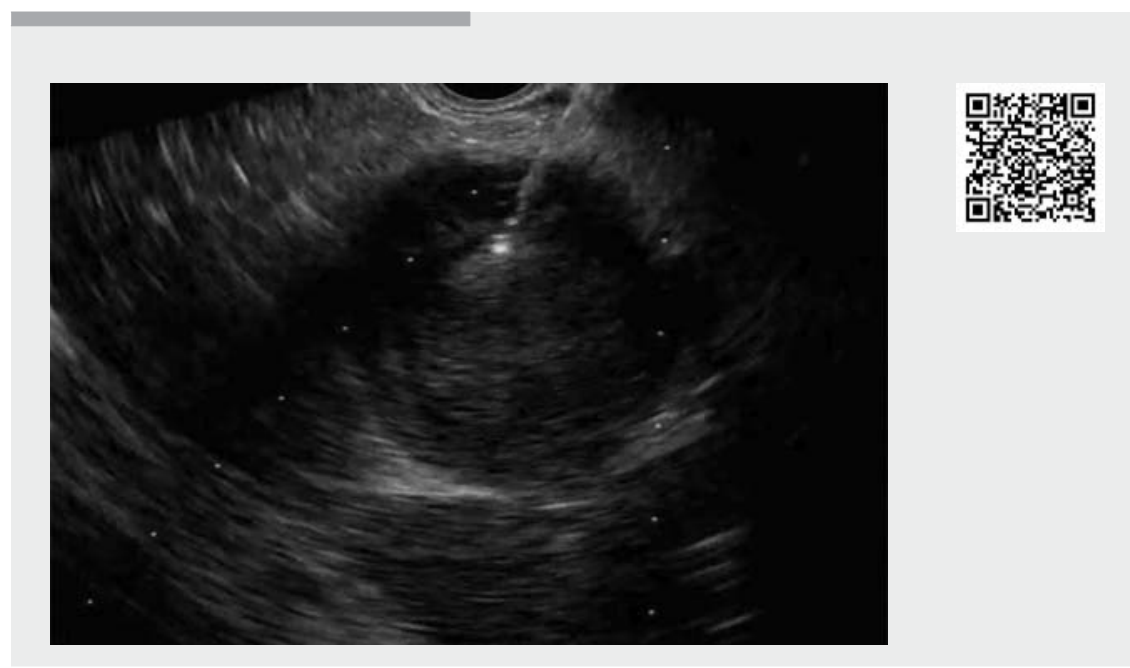

$\checkmark$ Video 1 Endoscopic ultrasonography-guided fine-needle biopsy (EUS-FNB) being performed on a hypoechoic lesion in the tail of the pancreas.

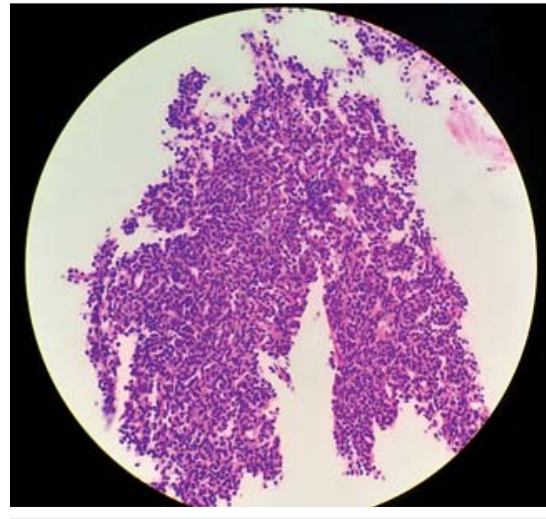

- Fig. 2 Pathological appearance of the biopsy specimen taken from the mass, which was diagnosed as being a solid pseudopapillary tumor.

atic lesions because it can obtain more specimens and has a higher diagnostic accuracy, with no difference in the reported incidence of complications [1]. We used the $22 \mathrm{G}$ needle to increase the diagnostic accuracy and technical success rate during the EUS-FNB procedure, while reducing complications [2].

We consider there are several possible reasons for the occurrence of serious

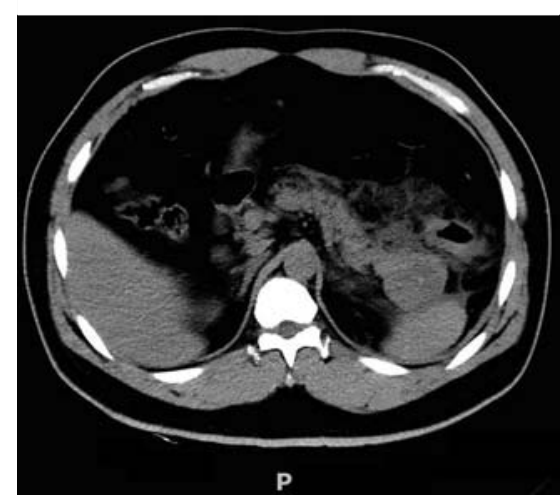

Fig. 3 Computed tomography scan of the abdomen showing exudation around the tail of the pancreas, confirming the diagnosis of acute pancreatitis.

complications. The side hole of the needle used may have obtained some tissue and increased the chance of cutting off the pancreatic duct. The CT scan shows that, although the pancreas is not obviously swollen, the extravasation of cystic fluid through the ruptured wall of the mass caused peritonitis. Excessive needle insertions and punctures may also cause pancreatitis [3]. This case sends a remin- 
der that the safety of EUS-FNB for cysticsolid lesions should be re-evaluated.

Endoscopy_UCTN_Code_CPL_1AL_2AD

\section{Acknowledgments}

Jun Yao is supported by the National Natural Science Foundation of China (No. 81800489); Li-sheng Wang is supported by Technical Research and Development Project of Shenzhen (No.JCYJ20170307100911479).

\section{Competing interests}

The authors declare that they have no conflict of interest.

The authors

Su Luo', De-feng Li' ${ }^{1}$, Liliangzi Guo², Lu Bai ${ }^{1}$, Li-sheng Wang ${ }^{1}$, Jun Yao ${ }^{1}$

1 Department of Gastroenterology, Shenzhen People's Hospital, Shenzhen, Guangdong, China

2 Department of Gastroenterology, The First Affiliated Hospital, Jinan University, Guangzhou, Guangdong, China
Corresponding author

\section{Jun Yao, MD}

Department of Gastroenterology, Jinan University of Second Clinical Medical Sciences, Shenzhen People's Hospital, 1017 East Gate Road, Shenzhen 518020 , Guangdong Province, China yj_1108@126.com

\section{References}

[1] Li H, Li W, Zhou QY et al. Fine needle biopsy is superior to fine needle aspiration in endoscopic ultrasound guided sampling of pancreatic masses: A meta-analysis of randomized controlled trials. Medicine 2018; 97: 13-18

[2] Li DF, Wang JY, Yang MF et al. Factors associated with diagnostic accuracy, technical success and adverse events of endoscopic ultrasound-guided fine-needle biopsy: A systematic review and meta-analysis. J Gastroenterol Hepatol 2020; 35: 1264-1276

[3] Lee KH, Kim EY, Cho J et al. Risk factors associated with adverse events during endoscopic ultrasound-guided tissue sampling. PloS One 2017; 12: 1-13
Bibliography

Endoscopy 2021; 53: E322-E323

DOI 10.1055/a-1275-9603

ISSN 0013-726X

published online 23.10.2020

(c) 2020. Thieme. All rights reserved.

Georg Thieme Verlag KG, Rüdigerstraße 14, 70469 Stuttgart, Germany

\section{ENDOSCOPY E-VIDEOS}

https://eref.thieme.de/e-videos

回回 Endoscopy E-Videos is a free access online section, reporting 靣: on interesting cases and new techniques in gastroenterological endoscopy. All papers include a high quality video and all contributions are freely accessible online.

This section has its own submission website at https://mc.manuscriptcentral.com/e-videos 